\title{
The molecular detection of different Leishmania species within sand flies from a cutaneous and visceral leishmaniasis sympatric area in Southeastern Brazil
}

\author{
Lara Saraiva1, José Dilermando Andrade Filho², Soraia de Oliveira Silva', \\ Antero Silva Ribeiro de Andrade ${ }^{3}$, Maria Norma Melo ${ }^{1 /+}$ \\ 1'Departamento de Parasitologia, Instituto de Ciências Biológicas \\ ${ }^{3}$ Centro de Desenvolvimento de Tecnologia Nuclear, Comissão Nacional de Energia Nuclear, \\ Universidade Federal de Minas Gerais, Belo Horizonte, MG, Brasil \\ ${ }^{2}$ Centro de Referência Nacional e Internacional para Flebotomíneos, Instituto de Pesquisas René Rachou-Fiocruz, Belo Horizonte, MG, Brasil
}

Over the last 20 years, there has been an increase in the number of leishmaniasis cases in Brazil. Belo Horizonte $(B H)$ is one of the most highly populated Brazilian cities that is affected by visceral leishmaniasis (VL). The health services in BH are coordinated by a central nucleus that is subdivided into nine sanitary districts. Historically, the highest level of human VL cases was found in the northeast sanitary district (NSD). The objective of our study was to detect Leishmania infection in the phlebotomine sand flies collected in the NSD by dissection and molecular approaches. Following the occurrence of human VL cases in 2005, entomological captures were performed from July 2006-June 2007. Out of the 245 sand flies dissected, only three Lutzomyia longipalpis spp contained flagellates. The female sand flies were grouped into 120 pools according to date, collection site and species, with approximately 10 individual sand flies in each pool. Subsquently, the DNA was extracted and Leishmania spp and other parasites were detected and identified by polymerase chain reaction (PCR) and PCR-restriction fragment length polymorfism. Leishmania infantum was present in at least $19 \%$ of the Lu. longipalpis collected, in 3.8\% of the Nyssomiya whitmani collected, in 33.3\% of the Evandromiya termitophila collected and in $14.3 \%$ of the Nyssomiya intermedia collected. When the females of the cortelezzii complex were compared with each other, $3.2 \%$ of the females were infected with Leishmania braziliensis, whereas $3.2 \%$ of the females were infected with trypanosomatids.

Key words: Leishmania spp - sand flies - natural infection - Belo Horizonte

Several leishmaniasis studies have used molecular techniques to detect, identify and characterize Leishmania in humans and reservoirs (Degrave et al. 1994, Cortes et al. 2004, Volpini et al. 2004, Carvalho et al. 2008). Molecular techniques are highly sensitive in the detection of Leishmania spp infections in phlebotomines. This sensitivity increases the understanding of the vector competence and leishmaniasis epidemiology (Aransay et al. 2000, Perruolo et al. 2006).

At the complex level, the identification of Leishmania spp in phlebotomines has employed various molecular techniques such as polymerase chain reaction (PCR), PCR-restriction fragment length polymorphism (PCRRFLP) and probe hybridization (Volpini et al. 2004, de Pita-Pereira et al. 2005, Carvalho et al. 2008). Several DNA targets such as the rRNA gene, minexon-derived RNA gene, repeated genome sequences and the kDNA minicircle (Aransay et al. 2000, Paiva et al. 2006) are used in the PCR detection and identification of Leishmania spp.

Financial support: LeishEpiNetSA (015407), CAPES, CNPq

+Corresponding author: melo@icb.ufmg.br

Received 13 July 2010

Accepted 27 October 2010
Sensitivity and specificity are the main advantages of molecular methods regardless of the number, stage and location of the parasites in the phlebotomine digestive tract (Perez et al. 1994, de Pita-Pereira et al. 2005). Even in situations where excess insect DNA exists, the presence of a single parasite is enough for DNA detection by PCR (de Bruijn \& Barker 1992). Several studies using molecular methods to evaluate Leishmania infection rates in phlebotomines have been performed in Brazil (de Pita-Pereira et al. 2005, 2008, Paiva et al. 2006, Kato et al. 2007, Carvalho et al. 2008, Saraiva et al. 2009, Rocha et al. 2010). In addition, studies in other trypanosomatids have been reported (Wallace \& Hertig 1968, Arias et al. 1985, Naiff et al. 1989).

Leishmaniasis has occurred in record numbers in several Brazil states (Souza et al. 2009). The detection and identification of Leishmania spp in naturally infected sand flies is important for disease prevention and to understand leishmaniasis epidemiology (Michalsky et al. 2002).

In several Brazilian cities, visceral leishmaniasis (VL) has become a serious public health problem. City urbanization and the adaptation of Lutzomyia longipalpis to the peridomicile have been linked to environmental changes as well as the migration, interaction and spread of sylvatic reservoirs and infected dogs to normally low transmission areas. Recently, VL outbreaks and epidemics have been reported in large Brazilian cities such as Belo Horizonte (BH), which is the capital of the state of Minas Gerais (MG) (MS 2006). 
Phlebotomine fauna studies in $\mathrm{BH}$ have demonstrated the presence of vectors for American cutaneous leishmaniasis (ACL) and VL (Souza et al. 2004, Resende et al. 2006). In a study performed in BH from 2001-2003, Souza et al. (2004) reported the presence of the important leishmaniasis vectors $L u$. longipalpis, $N y$ ssomiya whitmani and Nyssomiya intermedia. However, they did not detect the presence of Leishmania in these sand fly species. Here, we studied the Leishmania spp infection rates in the phlebotomine population of BH's northeast sanitary district (NSD). We used DNA-based techniques to identify the Leishmania spp in an area where both ACL and VL are present.

\section{SUBJECTS, MATERIALS AND METHODS}

Study areas and phlebotomine collection - The research was performed in the Southeast region of Brazil $\left(19^{\circ} 55^{\prime} \mathrm{S} 43^{\circ} 57^{\prime} \mathrm{W}\right)$ in $\mathrm{BH}$. With a population of over 2.4 million people, $\mathrm{BH}$ is the fifth largest city in the country. This high-altitude city has a tropical wet and dry climate that corresponds to the Aw and As Köppen climate classification categories. The average annual temperature is approximately $21^{\circ} \mathrm{C}$. The health services are coordinated by a central nucleus that is subdivided into nine sanitary districts encompassing the north, northeast, east, south central, west, Venda Nova, Pampulha and Barreiro.

Our study has been performed in the NSD, which has a population of 274,060 , distributed into 69 neighbourhoods. Its territorial extension is $39.60 \mathrm{~km}^{2}$ and has $19.46 \mathrm{~km}^{2}$ of green area (PBH 2008) (Fig. 1). This is an endemic area of human and canine VL and cutaneous leishmaniasis. With 257 cases between 1994-2009, the NSD accumulated the highest number of human VL cases in BH. In 2006, 2007 and 2008, 23, 21 and 41 cases of VL occurred, respectively, with five cases resulting in death. The positive tests for canine leishmaniasis were high, reaching $10 \%$. In each sanitary district of BH, several ACL cases were registered, but none were reported: in 2007, 25 cases were registered, in 2008, 27 cases, and in 2009, 44 cases (SINAN 2010).
The entomological study was performed from July 2006-June 2007. Phlebotomine sand flies were collected in the peridomestic area of residences where human VL cases had been reported in 2005 and in two green areas that were close to the urban areas. The insects were captured by 24 HP light traps (Pugedo et al. 2005) that were placed overnight from 6:00 pm-8:00 am. Using a Shannon light trap, one collection was performed each season, for a total of four collections.

Processing and packaging of collected phlebotomines - All phlebotomines were identified according to the Galati classification system (Galati 2003). The male specimens were prepared and mounted. The female specimens were subjected to dissection and DNA extraction. Subsquently, the extracted DNA was used in the PCR and PCR-RFLP reactions to identify the Leishmania spp.

Sand fly dissection was performed following a modification of a method by Carvalho (1973). The female specimens were immersed in Mycostatin (Squibb) solution at $100,000 \mathrm{U} / \mathrm{mL}$ for $15 \mathrm{~min}$, immersed in a benzalkonium chloride solution (1:1000) (Zephiran, Winthrop) for $2 \mathrm{~min}$ and washed twice with sterile distilled water. All instruments and solutions were sterilized and the immersion and washing steps were performed in laminar flow. All insects were dissected in saline with $50 \mathrm{U} / \mathrm{mL}$ of amikacin sulphate on a glass slide and the digestive tract was examined under an optical microscope with 400X magnification.

The female digestive tract halves that had flagellates forms in the gut were transferred to an Eppendorf tube with saline containing $50 \mathrm{U} / \mathrm{mL}$ of amikacin sulphate. The tube was centrifuged at $500 \mathrm{~g}$ in an Eppendorf 5415 microcentrifuge for $5 \mathrm{~min}$ and then the supernatant was discarded. The pellet was resuspended in $300 \mu \mathrm{L}$ of liver infusion tryptose (LIT) medium and transferred to tubes containing Novy-MacNealNicolle plus LIT.

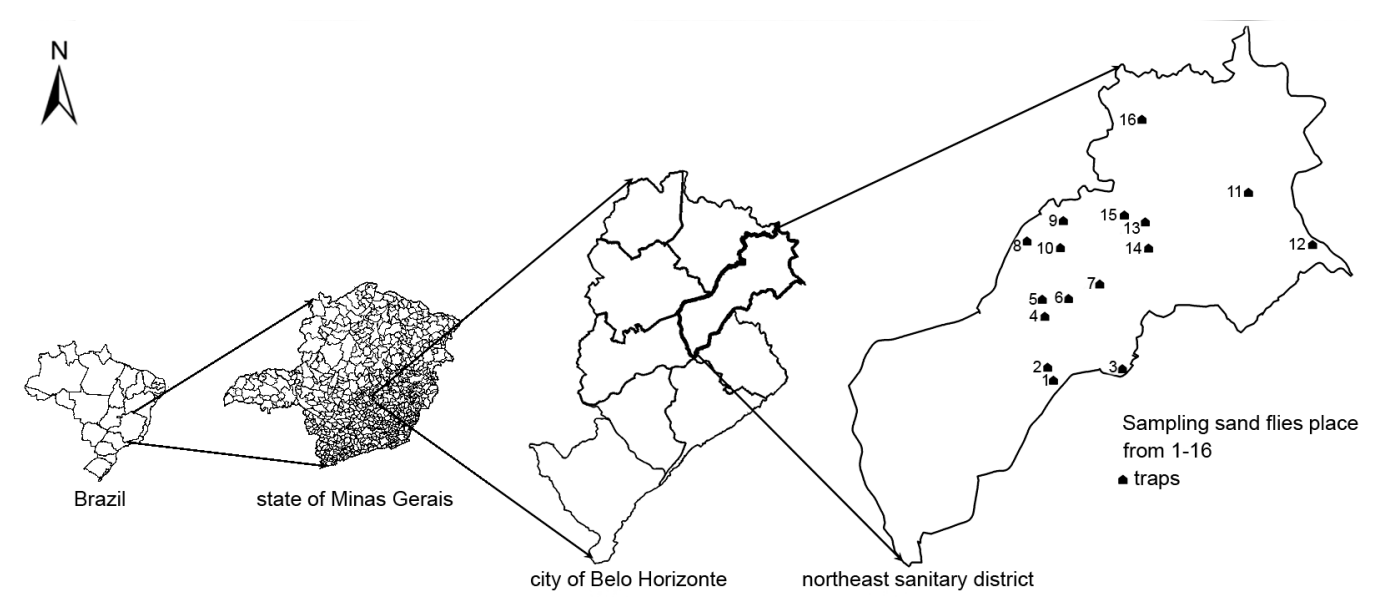

Fig. 1: administrative division of the municipal district of Belo Horizonte (BH), its location in the state of Minas Gerais and in Brazil, the location of the northeast sanitary district in BH and of the phlebotomine sampling sites in this regional from July $2006-J u n e$ 2007. 11, 12: green areas; 1-10, 13-16: urban areas. 
The other half of the material was stored in Eppendorf tubes and frozen at $-70^{\circ} \mathrm{C}$ for the execution of the molecular assays. Females that did have flagellated forms in their gut were frozen. Depending on the number of specimens collected, females of the same species that were from the same trap and the same collection date were processed individually or in pools that contained up to 10 specimens. Female sand flies that had blood and flagellated forms in their digestive tracts were processed individually. The DNA was extracted using the Gentra Puregene Blood Kit (Qiagen) according to the manufacturer's instructions.

Primers that amplified the IVS6 region of the cacophony gene of new world sand flies (5'-GTGGCCGAACATAATGTTAG-3' and 5'-CCACGAACAAGTTCAACATC-3') (Lins et al. 2002), were used to test the samples by PCR to exclude the possibility of PCR inhibition and to serve as a control for the extraction procedure. Two microlitres of hydrated DNA solution from each sample was added to PCR reactions that were performed with the GoTaq Green Master Mix PCR kit (Promega). The protocol was based on a study by de Pita-Pereira et al. (2005). Ten microlitres of amplified product was examined by electrophoresis on $2 \%$ agarose gel stained with ethidium bromide, visualized under ultra-violet transillumination and photographed. A positive control (DNA obtained from a Lu. longipalpis that was reared in the laboratory) and a negative control (a reaction without DNA) were used in all reactions.

Using a protocol adapted from de Pita-Pereira et al. (2005), primers that amplified the 120-bp sequence corresponding to the conserved region of Leishmania kDNA (5'CCG CCCCTATTTTACACCAACCCC3', 5'GGCCCACTATATTACACCAACCCC3' and 5'GGGGAGGGG GGTTCTGCGAA3') (Michalsky et al. 2002) were utilized to evaluate the presence of Leishmania DNA in all samples. The $10 \mu \mathrm{L}$ PCR reaction was composed of $1 \mu \mathrm{L}$ of dNTPs, $1 \mu \mathrm{L}$ of enzyme buffer (Applied Biosystem, Roche), $0.6 \mu \mathrm{L}$ of magnesium chloride (Applied Biosystem, Roche), $0.2 \mu \mathrm{L}$ of Taq Gold (Applied Biosystem, Roche), $1 \mu \mathrm{L}$ ( $5 \mathrm{pmol}$ ) of each initiator, $5.2 \mu \mathrm{L}$ of water (double distilled and deionised) and $1 \mu \mathrm{L}$ of sample DNA. A 5\% polyacrylamide gel was used to electrophorese $4 \mu \mathrm{L}$ of the amplified product and then the gel was stained with silver for visualization.

The amplified PCR product was digested with Hae III and analyzed in a $10 \%$ agarose gel to identify individual Leishmania spp in sand flies or a pool of sand flies. Digestion with this endonuclease distinguishes the Leishmania amazonensis, Leishmania braziliensis and Leishmania infantum species (Volpini et al. 2004, de Andrade et al. 2006). Following the method described by de Andrade et al. (2001), a hybridization reaction of the PCR products (DOT-BLOT) was used to confirm the results of the PCR-RFLP. Because the exact rate of natural Leishmania infections in the positive pools was not known, it was assumed that only one female in each positive pool was infected. This procedure is adopted by many authors as the minimum infection rate (Paiva et al. 2006).

\section{RESULTS}

Out of the 245 female specimens that were dissected, only three of the specimens had flagellated forms freely moving in the middle portion of the intestine. These females were Lu. longipalpis spp and came from collection point 15 , which was a house in an urban area (Table I). Because of contamination, it was not possible to isolate the flagellated forms in culture medium.

Both Evandromyia sallesi and Evandromyia cortelezzii females were identified as belonging to the cortelezzii complex. Because these sand flies are indistinguishable by morphological characteristics (Carvalho et al. 2009), the procedure was adopted.

During DNA extraction, the females were grouped into 120 samples. All of the samples amplified the $200 \mathrm{bp}$ fragment corresponding to the cacophony gene, which was expected by PCR. The presence of the $200 \mathrm{bp}$ fragment confirmed the high quality of the DNA obtained from all samples.

Using the primers described by Michalsky et al. (2002), 15 samples tested positive for Leishmania spp (Fig. 2). Among the positive samples, tree females (analyzed individually) had blood in the digestive tract; one sample was $\mathrm{Lu}$. longipalpis, one sample was $N y$. whitmani and one sample was $N y$. intermedia (Table I).

Twelve PCR product samples had restriction fragments characteristic of $L$. infantum (120 bp, $80 \mathrm{bp}, 60 \mathrm{bp}, 40 \mathrm{bp}$ ) following digestion with Hae III and one sample had a restriction fragment profile ( $80 \mathrm{bp}$ and $40 \mathrm{bp}$ ) characteristic of $L$. braziliensis. Using this technique, there were no conclusive restriction fragment profiles for samples 47 and 70 (Fig. 3).

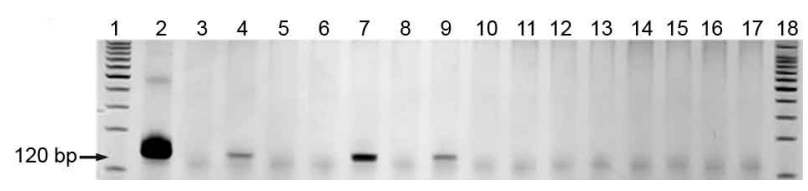

Fig. 2: silver stained polyacrylamide gel (5\%) showing the polymerase chain reaction products with initiators for the conserved region kDNA minicircle of Leishmania sp. in DNA samples extracted from phlebotomine females. Lanes 1, 18: standard molecular weight $100 \mathrm{bp} ; 2$ : positive control (DNA from promastigotes of Leishmania infantum (MHOM/BR/1967/BH46); 3: negative control without DNA; 4-17: samples relating to collection of July 2007.

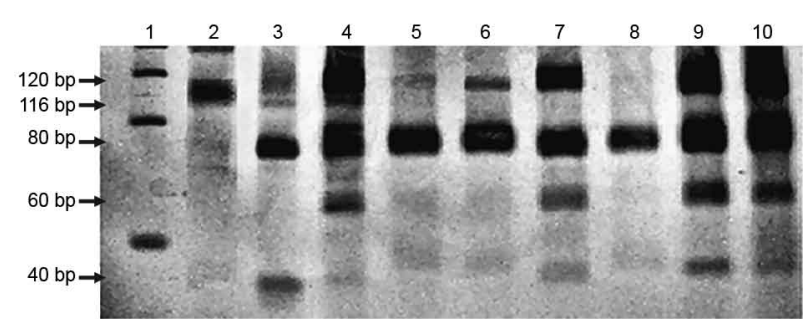

Fig. 3: polyacrylamide gel (10\%), silver stained, showing the polymerase chain reaction-restriction fragment length polymorfism products. Lane 1: standard molecular weight 50 bp; 2: strain PH8 of Leishmania amazonensis; 3: strain M2903 of Leishmania braziliensis; 4: strain PP75 of Leishmania infantum; 5-10: samples positive to L. infantum. 
1036 Leishmania spp within sand flies in Minas Gerais - Lara Saraiva et al.

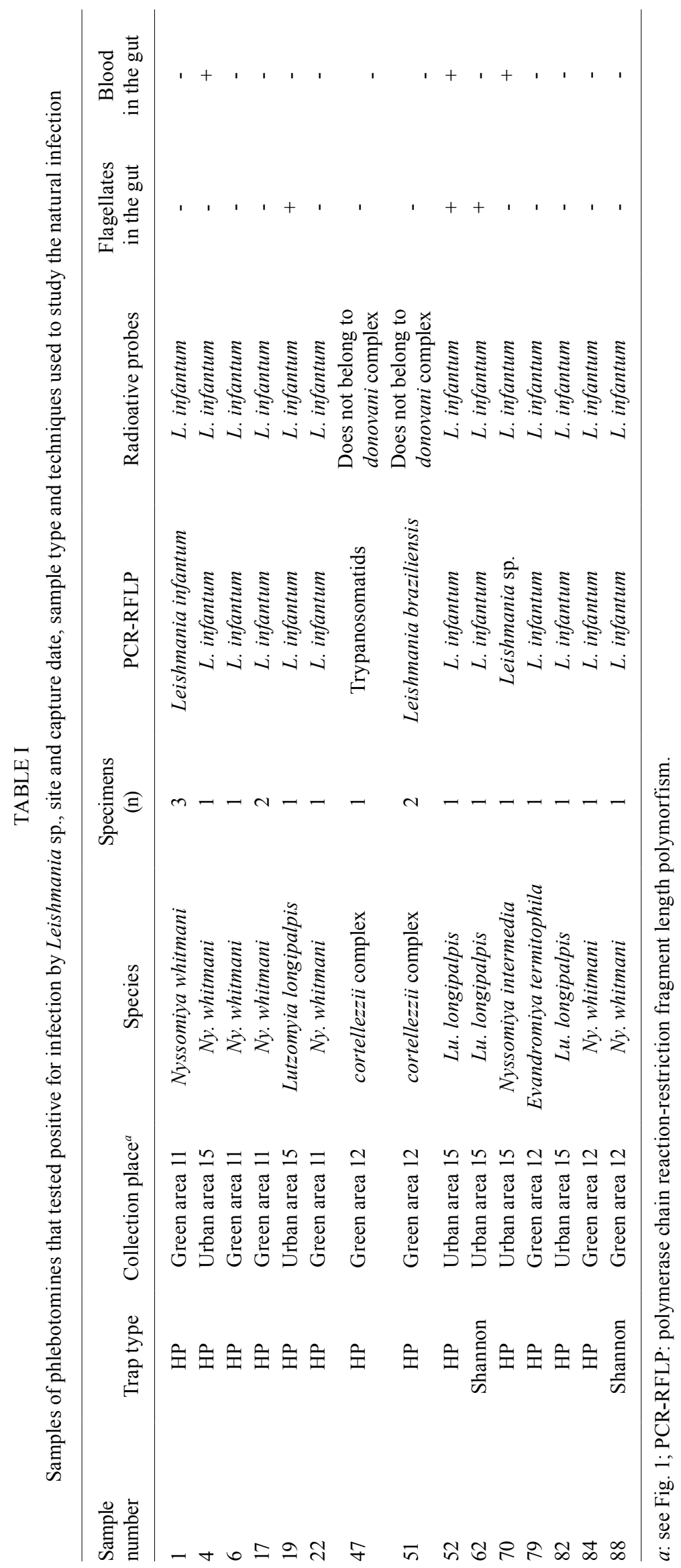


Most of the sand fly infections were caused by $L$. infantum and the sand fly infection rates for this species were as follows: $19 \%$ infected with Lu. longipalpis (4 positive samples and 1 sample with blood in the gut), $3.8 \%$ infected with $\mathrm{Ny}$. whitmani (7 positive samples and 1 individual with blood in the gut), $33.3 \%$ infected with Evandromyia termitophila and $14.3 \%$ infected with $N y$. intermedia (1 positive sample with blood in the gut). For the cortelezzii complex, the sand fly infection rates were $3.2 \%$ infected with L. braziliensis and 3.2\% infected with trypanosomatids (Table II).

Because the majority of the samples were characterized by PCR-RFLP as $L$. infantum, the samples were verified by a hybridization technique that used ${ }^{32} \mathrm{P}$-labelled probes for the entire minicircle of the Leishmania donovani complex. Sample 70 tested positive by hybridization for $L$. infantum (L. donovani complex), whereas sample 47 tested negative by hybridization for $L$. infantum (L. donovani complex) (Table I).

\section{DISCUSSION}

Compared with some studies that used molecular approaches, the infection rates encountered in the phlebotomines from the NSD were high (Rodríguez et al. 1999, Luz et al. 2000). In the NSD, the highest $L$. infantum infection rate (19\%) was found in Lu. longipalpis, which is the main vector of this species in Brazil. When compared to similar studies in other parts of Brazil, this infection rate is much higher. For example, Paiva et al. (2006) observed a L. infantum infection rate of $3.9 \%$ in Lu. longipalpis in the state of Mato Grosso do Sul by PCR, while Savani et al. (2009) observed a 0.25\% infection rate of Lu. longipalpis by L. infantum and an infection rate of $1.25 \%$ by $L$. amazonensis.

We suggest three factors that could be responsible for the high infection rates observed in this study: (i) the majority of the samples were collected from the peridomiciles where human VL cases occurred in 2005, (ii) the high Leishmania spp infection rate (Oliveira et al. 2006) of the phlebotomines could be due to the favourable environmental conditions for vector development and the high prevalence of canine infection (in areas where zoonotic VL occurs, domestic dogs are considered to be the most important infection source for phlebotomines) and (iii) molecular methods are more sensitive than the specific techniques traditionally used.

In the present study, the rates of $L$. infantum infection for $N y$. whitmani and $N y$. intermedia were $3.8 \%$ and $14.3 \%$, respectively. This is the first report of $L$. infantum infection in these phlebotomine species. Ny. whitmani was the species most frequently captured in the area and PCR has previously shown that $N y$. whitmani found in the metropolitan area of BH is infected with L. braziliensis (Carvalho et al. 2008). In the municipal district of Rio de Janeiro, de Pita-Pereira et al. (2005) has calculated that $N y$. intermedia has a L. braziliensis infection rate of $15.6 \%$. In Brazil, both of these species are the main vectors of $L$. braziliensis (Lainson \& Rangel 2003). It is interesting to note that Nyssomiya neivai, a species that is phylogenetically close to $N y$. intermedia (Marcondes 1996, Andrade Filho et al. 2003), has been shown to be infected with $L$. infantum north of MG (Saraiva et al. 2009). These species have similar habitats and are found in sympatry in some localities (Andrade Filho et al. 2007, Saraiva et al. 2008).

For the Ny. whitmani samples with and without blood in the gut, both PCR and hybridization reactions were positive for $L$. infantum. The hybridization reaction was positive in an individual $N y$. intermedia sample that had blood in the gut. Unlike $N y$. intermedia, these results suggest that $L$. infantum could colonize the $N y$. whitmani gut.

Comparing the three Ev. termithopila specimens collected in this study, one had an L. infantum infection rate of $33.3 \%$. Given the small number of insects collected, this result should be analyzed carefully. To the best of our knowledge, the infection of Ev. termithopila by any Leishmania spp has not been studied.

The cortelezzii complex specimens were naturally infected by L. braziliensis and trypanosomatids. This is the first report on L. braziliensis infection of females of the cortelezzii complex and it demonstrates the presence and circulation of this parasite regionally. In MG, both Carvalho et al. (2008) and Saraiva et al. (2009) encountered $L$. infantum-infected Ev. cortelezzii and Ev. sallesi.

Infected specimens from the cortelezzii complex were collected in the green area of collection point 12

TABLE II

Positivity rates for Leishmania by phlebotomine species and sample type

\begin{tabular}{lcccc}
\hline & $\begin{array}{c}\text { Specimens } \\
\text { collected } \\
\text { Species }\end{array}$ & $\begin{array}{c}\text { Infected } \\
\text { specimens/groups } \\
\text { (n) }\end{array}$ & $\begin{array}{c}\text { Positivy rates } \\
\text { for Leishmania } \\
(\%)\end{array}$ & $\begin{array}{c}\text { Leishmania species } \\
\text { Nyssomiya whitmani }\end{array}$ \\
Lutzomyia longipalpis & 181 & 7 & Leishmania infantum & 3.80 \\
Complexo cortelezzii & 21 & 1 & L. infantum & 19 \\
Complexo cortelezzii & 31 & 1 & Trypanosomatids & 3.20 \\
Nyssomiya intermedia & 31 & 1 & L. infantum & 3.20 \\
Evandromiya termitophila & 7 & 1 & L. infantum & 14.30 \\
& 3 & & & 33.30
\end{tabular}


(Table I). In this same area and study period, 16 small mammal specimens, which included rodents and carnivores, were collected and were positively infected with L. braziliensis (LA Melo 2008, personal communication). Further studies on the behaviour of the cortelezzii complex species are necessary so that their possible participation in the local L. braziliensis transmission cycle can be determined.

Although we have used a highly sensitive PCR to detect the conserved region of the kDNA minicircle in infected sand flies (de Pita-Pereira et al. 2005, Carvalho et al. 2008), we used other molecular techniques to confirm the etiological identification, PCR-RFLP and hybridization. We also knew that trypanosomatids other than Leishmania would be present in the wild sand flies (Wallace \& Hertig 1968, Arias et al. 1985, Naiff et al. 1989) and recent studies (Rocha et al. 2010) have shown that PCR-RFLP is unable to differentiate some Leishmania species from other trypanosomatids. In this study, the trypanosomatids that were present in the cortelezzii complex could be Leishmania spp other than L. infantum or L. braziliensis or other trypanosomatids that could be found in these sand flies.

When the results obtained by the molecular techniques and the observation of dissected intestines by microscope were compared, only three specimens were positive for Leishmania in by microscopic analyses, whereas 15 tested positive by molecular techniques, including the previous three mentioned above. This represents a $500 \%$ increase in the number of positive results obtained when the techniques are compared. This result illustrates why molecular techniques are considerably more sensitive and specific in Leishmania detection in sand flies.

The samples characterized as $L$. infantum by PCR-RFLP have been confirmed by the hybridization with radioactive probes, which are successfully used in the identification of Leishmania in vertebrate and phlebotomine tissues (de Pita-Pereira et al. 2005, Oliveira et al. 2005, de Andrade et al. 2006).

These results reveal an important circulation of $L$. infantum in the ecotopes studied in the NSD. Phlebotomine species that have never been shown to be infected naturally by any Leishmania species tested positive for L. infantum.

Because of the recent development of VL in Brazil, the characteristics of VL urbanization in the NSD must be studied in more detail. In addition, health authorities should consider a possible outbreak of urban or peri-urban L. braziliensis.

It is important to note that the occurrence of a natural infection is not enough to define a species as a vector in the leishmaniasis cycle. To define a phlebotomine species as the vector of a particular Leishmania sp., it must fit the parameters described by Killick-Kendrick (1990) and must be accepted and adopted by the Brazil Ministry of Health (MS 2007). Thus, these data only attest to the circulation of $L$. infantum and do not mean that $N y$. whitmani, $N y$. intermedia and Ev. termitophila are its vectors. Similarly, the cortellezzi complex can not be considered a vector of $L$. braziliensis.

\section{ACKNOWLEDGEMENTS}

To Northeast community, to the collaboration in the field sampling process, and to David Lee Nelson, by the English language review.

\section{REFERENCES}

Andrade Filho JD, Galati EAB, Falcão AL 2007. Nyssomyia intermedia (Lutz \& Neiva, 1912) and Nyssomyia neivai (Pinto, 1926) (Diptera: Psychodidae: Phlebotominae) geographical distribution and epidemiological importance. Mem Inst Oswaldo Cruz 102: 481-487.

Andrade Filho JD, Galati EAB, Falcão AL 2003. Redescription of Nyssomyia intermedia (Lutz \& Neiva, 1912) and Nyssomyia neivai (Pinto, 1926) (Diptera: Psychodidae). Mem Inst Oswaldo Cruz 98: 1059-1065.

Aransay AM, Scoulica E, Tselentis Y 2000. Detection and identification of Leishmania DNA within naturally infected sand flies by seminested PCR on minicircle kinetoplastic DNA. Appl Environ Microbiol 66: 1933-1938.

Arias JR, Miles MA, Naiff RD, Povoa MM, de Freitas RA, Biancardi CB, Castellon EG 1985. Flagellate infections of Brazilian sand flies (Diptera: Psychodidae): isolation in vitro and biochemical identification of Endotrypanum and Leishmania. Am J Trop Med Hyg 34: 1098-1108.

Carvalho ALM 1973. Estudos sobre a posição sistemática, a biologia e a transmissão de tripanosomatídeos encontrados em Zelus leucogrammus (Perty, 1834) - (Hemiptera, Reduviidae), Thesis, Universidade Federal de Minas Gerais, Belo Horizonte, $82 \mathrm{pp}$.

Carvalho GM, Andrade Filho JD, Falcao AL, Rocha Lima, AC, Gontijo CM 2008. Naturally infected Lutzomyia sand flies in a Leishmania-endemic area of Brazil. Vector Borne Zoonotic Dis 8: 407-414.

Carvalho GML, Brazil RP, Falcão AL, Andrade Filho JD 2009. Distribuição geográfica do complexo cortelezzii (Diptera: Psychodidae: Phlebotominae) no Brasil. Neotrop Entomol 38: 876-879.

Cortes S, Rolão N, Ramada J, Campino L 2004. PCR as a rapid and sensitive tool in the diagnosis of human and canine leishmaniasis using Leishmania donovani s.1.-specific kinetoplastid primers. Trans R Soc Trop Med Hyg 98: 12-17.

de Andrade AS, Gomes RF, Fernandes O, de Melo MN 2001. Use of DNA-based diagnostic methods for human leishmaniasis in Minas Gerais, Brazil. Acta Trop 78: 261-267.

de Andrade HM, Reis AB, dos Santos SL, Volpini AC, Marques MJ, Romanha AJ 2006. Use of PCR-RFLP to identify Leishmania species in naturally-infected dogs. Vet Parasitol 140: 231-238.

de Bruijn MH, Barker DC 1992. Diagnosis of New World leishmaniasis: specific detection of species of the Leishmania braziliensis complex by amplification of kinetoplast DNA. Acta Trop 52: 45-58.

de Pita-Pereira D, Alves CR, Souza MB, Brazil RP, Bertho AL, de Figueiredo Barbosa A, Britto CC 2005. Identification of naturally infected Lutzomyia intermedia and Lutzomyia migonei with Leishmania (Viannia) braziliensis in Rio de Janeiro (Brazil) revealed by a PCR multiplex non-isotopic hybridisation assay. Trans R Soc Trop Med Hyg 99: 905-913.

de Pita-Pereira D, Cardoso MA, Alves CR, Brazil RP, Britto C 2008. Detection of natural infection in Lutzomyia cruzi and Lutzomyia forattinii (Diptera: Psychodidae: Phlebotominae) by Leishmania infantum chagasi in an endemic area of visceral leishmaniasis in Brazil using a PCR multiplex assay. Acta Trop 107: 66-69. 
Degrave W, Fernandes O, Campbell D, Bozza M, Lopes U 1994. Use of molecular probes and PCR for detection and typing of Leishmania - a mini-review. Mem Inst Oswaldo Cruz 89: 463-469.

Galati EAB 2003. Classificação de Phlebotominae. In EF Rangel, R Lainson, Flebotomíneos do Brasil, Fiocruz, Rio de Janeiro, p. 23-51.

Kato H, Uezato H, Gomez EA, Terayama Y, Calvopiña M, Iwata H, Hashiguchi Y 2007. Establishment of a mass screening method of sand fly vectors for Leishmania infection by molecular biological methods. Am J Trop Med Hyg 77: 324-329.

Killick-Kendrick R 1990. Phlebotomine vectors of the leishmaniases: a review. Med Vet Entomol 4: 1-24.

Lainson R, Rangel EF 2003. Transmissores de leishmaniose tegumentar americana. In EF Rangel, R Lainson, Flebotomíneos do Brasil, Fiocruz, Rio de Janeiro, p. 291-310.

Lins RM, Oliveira SG, Souza NA, de Queiroz RG, Justiniano SC, Ward RD, Kyriacou CP, Peixoto AA 2002. Molecular evolution of the cacophony IVS6 region in sandflies. Insect Mol Biol 11: 117-122.

Luz E, Membrive N, Castro EA, Dereure J, Pratlong F, Dedet JA, Pandey A, Thomaz-Soccol V 2000. Lutzomyia whitmani (Diptera: Psychodidae) as vector of Leishmania (V.) braziliensis in Paraná state, Southern Brazil. Ann Trop Med Parasitol 94: 623-631.

Marcondes CB 1996. A redescription of Lutzomyia (Nyssomyia) intermedia (Lutz \& Neiva, 1912), and resurrection of L. neivai (Pinto, 1926) (Diptera, Psychodidae, Phlebotominae). Mem Inst Oswaldo Cruz 91: 457-462.

Michalsky EM, Fortes-Dias CL, Pimenta PF, Secundino NF, Dias ES 2002. Assessment of PCR in the detection of Leishmania spp in experimentally infected individual phlebotomine sandflies (Diptera: Psychodidae: Phlebotominae). Rev Inst Med Trop Sao Paulo 44: $255-259$

MS - Ministério da Saúde, Brasil 2006. Manual de vigilância e controle da leishmaniose visceral, Ministério da Saúde (acessed 5 April 2008). Available from: http://Portal.Saude.Gov.Br/Portal/ Arquivos/Pdf/Manual_Leish_Visceral2006.pdf.

MS - Ministério da Saúde, Brasil 2007. Manual de vigilância e controle da leishmaniose tegumentar, Ministério da Saúde (accessed 12 June 2010). Available from: http://portal.saude.gov.br/portal/ arquivos/pdf/manu_leishman.pdf.

Naiff RD, Barrett TV, Freitas RA 1989. Isolation of Trypanosoma freitasi (Kinetoplastida: Trypanosomatidae) from Psychodopygus claustrei (Diptera: Psychodidae). Mem Inst Oswaldo Cruz 84: 273-275.

Oliveira EMD, Rosales Rodriguez CA, Leão SC, Amaku M, Ferreira Neto JS 2006. Estudo da dinâmica da infecção por Mycobacterium avium em uma população suína através de modelagem matemática. Arq Inst Biol (Sao Paulo) 73: 409-414.

Oliveira FS, Pirmez C, Pires MQ, Brazil RP, Pacheco RS 2005. PCRbased diagnosis for detection of Leishmania in skin and blood of rodents from an endemic area of cutaneous and visceral leishmaniasis in Brazil. Vet Parasitol 129: 219-227.

Paiva BR, Secundino NF, Nascimento JC, Pimenta PF, Galati EA, Junior HF, Malafronte RS 2006. Detection and identification of Leishmania species in filed-captured phlebotomine sandflies based on mini-exon gene PCR. Acta Trop 99: 252-259.

PBH - Prefeitura de Belo Horizonte - Regionais - Regional Nordeste 2008. Available from: http://portal2. pbh.gov.br/pbh/index. html?id_conteudo $=9479 \&$ id_nivell $=-1 \&$ ver_servico $=\mathrm{N}$ (accessed March 2008).

Perez JE, Ogusuku E, Inga R, Lopez M, Monje J, Paz L, Nieto E, Arevalo J, Guerra H 1994. Natural Leishmania infection of Lutzomyia spp in Peru. Trans R Soc Trop Med Hyg 88: 161-164.

Perruolo G, Noris Rodríguez N, Feliciangeli MD 2006. Isolation of Leishmania (Viannia) braziliensis from Lutzomyia spinicrassa (species group Verrucarum) Morales Osorno Mesa, Osorno and Hoyos 1969, in the Venezuelan Andean region. Parasite 13: 17-22.

Pugedo H, Barata RA, França-Silva JC, Silva JC, Dias ES 2005. HP: an improved model of suction light trap for the capture of small insects. Rev Soc Bras Med Trop 38: 70-72.

Resende MC, Camargo MC, Vieira JR, Nobi RC, Porto MN, Oliveira CD, Pessanha JE, Cunha M da C, Brandão ST 2006. Seasonal variation of Lutzomyia longipalpis in Belo Horizonte, state of Minas Gerais. Rev Soc Bras Med Trop 39: 51-55.

Rocha L de S, dos Santos CB, Falqueto A, Grimaldi G Jr, Cupolillo E 2010. Molecular biological identification of monoxenous trypanosomatids and Leishmania from antropophilic sand flies (Diptera: Psychodidae) in Southeast Brazil. Parasitol Res 107: 465-468.

Rodríguez N, Aguilar CM, Barrios MA, Barker DC 1999. Detection of Leishmania braziliensis in naturally infected individual sandflies by the polymerase chain reaction. Trans $R$ Soc Trop Med Hyg 93: 47-49.

Saraiva L, Carvalho GM, Gontijo CM, Quaresma PF, Lima AC, Falcão AL, Andrade Filho JD 2009. Natural infection of Lutzomyia neivai and Lutzomyia sallesi (Diptera: Psychodidae) by Leishmania infantum chagasi in Brazil. J Med Entomol 46: 1159-1163.

Saraiva L, Carvalho GML, Sanguinette CC, Carvalho DAA, Falcão AL, Andrade Filho JD 2008. Sandflies (Diptera: Pychodidae: Phlebotominae) collected on the banks of the Velhas River in the state of Minas Gerais, Brazil. Mem Inst Oswaldo Cruz 103: 843-846.

Savani ES, Nunes VL, Galati EA, Castilho TM, Zampieri RA, Floeter-Winter LM 2009. The finding of Lutzomyia almerioi and Lutzomyia longipalpis naturally infected by Leishmania spp in a cutaneous and canine visceral leishmaniases focus in Serra da Bodoquena, Brazil. Vet Parasitol 160: 18-24.

SINAN - Sistema Nacional de Agravos de Notificação 2010. Available from: http://dtr2004.saude.gov.br/sinanweb/index.php (accessed 12 June 2010).

Souza CM, Pessanha JE, Barata RA, Monteiro EM, Costa DC, Dias ES 2004. Study on phlebotomine sand fly (Diptera: Psychodidae) fauna in Belo Horizonte, state of Minas Gerais, Brazil. Mem Inst Oswaldo Cruz 99: 795-803.

Souza GD, Santos E, Andrade Filho JD 2009. The first report of the main vector of visceral leishmaniasis in America, Lutzomyia longipalpis (Lutz \& Neiva) (Diptera: Psychodidae: Phlebotominae), in the state of Rio Grande do Sul, Brazil. Mem Inst Oswaldo Cruz 104: 1181-1182.

Volpini AC, Passos VM, Oliveira GC, Romanha AJ 2004. PCR-RFLP to identify Leishmania (Viannia) braziliensis and L. (Leishmania) amazonensis causing American cutaneous leishmaniasis. Acta Trop 90: 31-37.

Wallace FG, Hertig M 1968. Ultrastructural comparison of promastigote flagellates (leptomonads) of wild-caught Panamaniam Phlebotomus. J Parasitol 54: 606-612. 